\title{
Long-Term Abundance and Distribution Trends of the Cladoceran Penilia avirostris in the US Northeast Shelf Ecosystem
}

\author{
Joseph Kane \\ NOAA, National Marine Fisheries Service \\ 28 Tarzwell Drive, Narragansett, Rhode Island, USA \\ Phone: 401-782-3244; Fax 401-782-3201; Email: joe.kane@noaa.gov
}

Kane, J. 2013. Long-Term Abundance and Distribution Trends of the Cladoceran Penilia avirostris in the US Northeast Shelf Ecosystem. J. Northw. Atl. Fish. Sci., 45: 1-10. doi:10.2960/J.v45.m682

\begin{abstract}
The average spatial distribution and interannual abundance patterns of the cladoceran Penilia avirostris are described from samples collected in the waters of the US Northeast continental shelf ecosystem. Integrated water column samples were collected with a bongo net from 1977-2009 on broad scale surveys of the shelf conducted approximately every two months. Collections were also made with a Continuous Plankton Recorder towed at $10 \mathrm{~m}$ depth along two routes; one that crossed the Gulf of Maine (1961-2009), and the other from New York City south-eastward toward Bermuda (1976-2009). P. avirostris was found to have a strong seasonal cycle in the southern half of the ecosystem. High coastal concentrations suddenly appear there in July-August, forming distinct onshore-offshore abundance gradients. The population slowly declines in the autumn months, essentially disappears from the zooplankton community during winter, and does not return again until its abrupt appearance in summer. Only low abundances in isolated patches were found in the northern half of the ecosystem and in the slope waters sampled by the CPR. Both samplers showed that annual abundance levels were variable with no long-term trend evident, nor were environmental measures or broad scale climate indices correlated to these variations. The cladocerans' summer population surge was significantly correlated with surface temperature and water column stratification indices. This is the first study to record the presence of $P$. avirostris in the Gulf of Maine region.
\end{abstract}

Keywords: abundance, distribution, Penilia avirostris, temperature, Gulf of Maine

\section{Introduction}

The marine cladoceran Penilia avirostris is seasonally abundant and distributed worldwide in the waters of tropical and subtropical oceans. Due to parthenogenetic reproduction and short generation times, $P$. avirostris populations can exhibit explosive growth and quickly eclipse the seasonal numbers and biomass of copepods that are usually more common in the same ecosystems. The cladoceran can persist year round in tropical waters, while it occurs seasonally in more temperate regions. The temperate populations will switch from parthenogenetic to sexual reproduction under adverse conditions, eventually producing resting eggs which sink to the bottom and hatch when conditions are more favorable again. Of the eight cladoceran species that have colonized the marine environment, $P$. avirostris is unique in that it is the only filter-feeder. This allows it to consume a wide range of prey size (Atienza et al., 2006), from minute nanoplankton $(2-20 \mu \mathrm{m})$ to larger cells $(>20 \mu \mathrm{m})$ that include dinoflagellates and diatoms.
Even though it is one of the most abundant zooplankton species found in nearshore waters of low and mid latitude regions, Penilia avirostris has not been widely studied and its importance to community dynamics appears to be under-appreciated. Research has focused primarily on copepods, which have traditionally been considered as the main link between primary producers and upper trophic levels in marine food webs. However, in tropical coastal waters annual production of $P$. avirostris has been estimated to be similar to the third most productive species in the copepod community (Rose et al., 2004). Moreover, $P$. avirostris probably plays a key role in food chain dynamics because it consumes organisms as small as bacterivorous flagellates (Katechakis et al., 2004), and is in turn fed on by carnivorous zooplankton, fish larvae, and planktivorous fish (Tang et al., 1995).

Recent reports indicate that Penilia avirostris appears to be extending its northward distribution on both sides of the Atlantic. In 1999, large numbers suddenly appeared in the North Sea for the first time and have now become 
a regular component of the region's autumn zooplankton community (Johns et al., 2005). The authors correlated the arrival with rising sea surface temperatures, and proposed that warmer conditions allowed resting eggs to survive through the winter, enabling them to establish a permanent population. The first appearance of $P$. avirostris in Canadian waters was reported for the Gulf of St. Lawrence in the autumns of 2000 and 2001 (Bernier and Locke, 2006). This represents a $5^{\circ}$ range extension $(1130 \mathrm{~km})$ from its previously reported northernmost occurrence on southeastern Georges Bank (Colton, 1985). The authors cautioned that this may not have been a natural extension of its distribution, but an expansion caused by ballast transport (Bernier and Locke, 2006).

NOAA Fisheries has monitored the zooplankton populations of the US Northeast Shelf Ecosystem since 1977 with dedicated broadscale surveys conducted approximately every two months (Sherman, 1980; Kane, 2011). Penilia avirostris has the fourth highest mean abundance $\left(12671 / 100 \mathrm{~m}^{3}\right)$ of all zooplankton taxa collected during the entire 1977-2009 time series. Zooplankton in the region has also been monitored with monthly surveys using a Continuous Plankton Recorder (CPR) along two transects that crossed northern and southern portions of the region from 1961 and 1976 onward, respectively (Jossi and Benway, 2003). In this paper, data from these two programs are combined to present an inter-decadal examination of the distribution and abundance variability of $P$. avirostris throughout the ecosystem. Furthermore, an attempt is made to couple the observed patterns with survey measurements of environmental variables and the variability of climatic indices.

\section{Methods}

\section{Broad Scale Surveys}

This analysis is based on the sorting results of 23795 zooplankton samples that were collected on broad scale surveys of the U.S. Northeast Shelf ecosystem for 33 years, 1977-2009 (Fig. 1). All samples were collected with

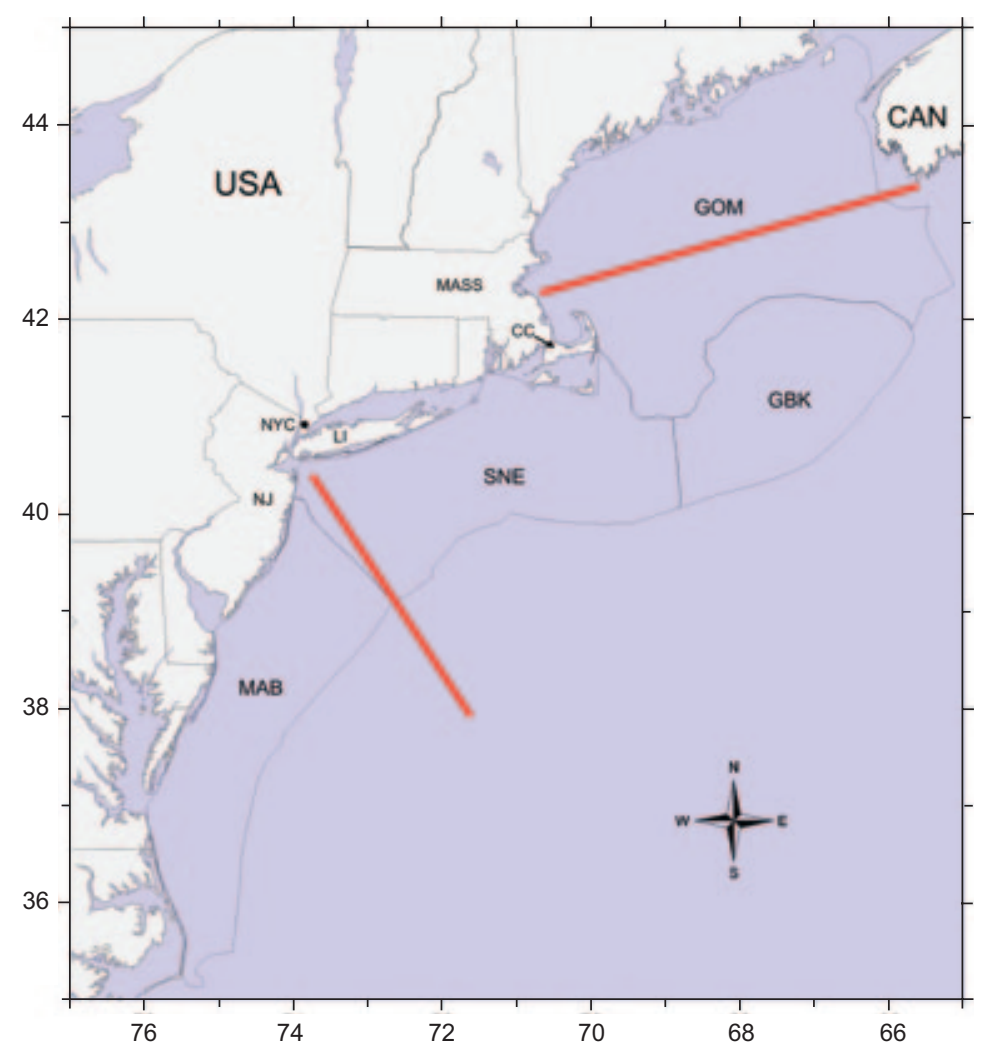

Fig. 1. Orientation map of area sampled during broad scale plankton surveys of the U.S. Northeast shelf ecosystem. The survey area was divided into four subareas: 1) Gulf of Maine (GOM), 2) Georges Bank (GBK), 3) Southern New England (SNE), and 4) Middle Atlantic Bight (MAB). The horizontal red lines are the approximate location of the Gulf of Maine and Mid-Atlantic CPR transects. Place name abbreviations: $\mathrm{NJ}=$ New Jersey, $\mathrm{NYC}=$ New York City, LI = Long Island, $\mathrm{CC}=$ Cape Cod, MASS $=$ Massachusetts) 
a $0.333 \mathrm{~mm}$ mesh net fitted on one side of a $61 \mathrm{~cm}$ Bongo frame that was equipped with a calibrated flowmeter to measure the volume of water filtered during the tow. The gear was towed at approximately 1.5 knots while it was lowered to within a few meters from the bottom, or to a maximum depth of $200 \mathrm{~m}$, and back to the surface. Cruise tracks and detailed sampling procedures for plankton and other measurements on surveys before 1988 were summarized by Sibunka and Silverman (1984, 1989). The only major change in sampling methodology after 1987 was attaching a CTD instrument above the Bongo frame to monitor the tow profile and collect simultaneous oceanographic data. The different survey sampling schemes employed during the time series have been described by Kane (2003).

Laboratory analysis began with the reduction of each sample to approximately 500 specimens with a modified box splitter. The aliquot was then sorted and zooplankton taxa were identified to the lowest taxonomic classification possible. Penilia avirostris life stages cannot be defined readily because they hatch from the egg as miniature adults and simply increase in size as they moult toward the adult stage. Therefore, all specimens were summed together and expressed here as numbers $/ 100 \mathrm{~m}^{3}$. Contoured bimonthly and seasonal distribution maps of abundance were generated using the Surfer 9 software package (Golden Software) to interpolate abundance surfaces with natural neighbor gridding methods.

Analysis of the cladocerans' abundance variability was facilitated by dividing the ecosystem into four subareas whose boundaries are defined by oceanographic characteristics (Ingham et al., 1982): the Gulf of Maine (GOM), Georges Bank (GBK), Southern New England (SNE), and the Middle Atlantic Bight (MAB) (Fig. 1). Interannual abundance variability was examined by calculating yearly abundance indices for each region. The data were $\log _{10}(\mathrm{n}+1)$ transformed and the average annual abundance cycle was computed by fitting a spline curve function to the time series bimonthly mean abundance values. Anomalies from the seasonal cycle were then averaged over each year to produce an annual abundance index. Sampling was too infrequent to calculate the annual anomaly in the MAB from 1989-94 and in the SNE region for 1989 .

\section{CPR Surveys}

Penilia avirostris abundance data were also analyzed from samples collected with a Continuous Plankton Recorder (CPR) towed at about $10 \mathrm{~m}$ depth (Hardy, 1939). Surveys were conducted at approximately monthly intervals along two transects across the ecosystem (Fig. 1). The Gulf of
Maine (GOM) transect extends from the Massachusetts coast across the Gulf of Maine to Cape Sable, Nova Scotia. Data were collected from 1961-2009, except for an interval from 1974-77. The Mid-Atlantic (MA) transect extends from just offshore of New York City, across the continental shelf and slope towards Bermuda. Data were collected from 1976-2009, with the exception of 1980.

The methods used on the CPR surveys along these two routes have been described by Jossi and Benway (2003). Briefly, plankton is filtered through bolting silk with a wetmesh aperture of $0.225 \mathrm{~mm} \times 0.234 \mathrm{~mm}$. In the laboratory, the silk was cut into pieces representing $18.5 \mathrm{~km}$ sections that were assigned geographic positions and reference distance values ( $\mathrm{km}$ from standard transect origin). Alternate sections of silk were examined for zooplankton using techniques described by Colebrook (Colebrook, 1975). CPR counts are reported here as numbers $/ 100 \mathrm{~m}^{3}$. Annual abundance anomalies were calculated using the same methods that were described earlier for broad scale surveys. Data collected along the MA transect were partitioned into shelf and slope water regions $(>200 \mathrm{~km}$ from transect origin) to facilitate comparisons with Bongo net surveys.

\section{Environmental Data}

Temperature and salinity measurements were routinely made on all broad scale surveys. Surface temperature measurements were made with a stem thermometer from a surface bucket sample from 1977-1998; values collected thereafter were recorded via a thermistor attached to the vessel. Samples for bottom temperature, surface salinity, and bottom salinity were collected with Niskin bottles from 1977-1986, while later years collected data with a CTD instrument. Annual anomalies for these variables were calculated using the same methods described earlier for the zooplankton abundance index.

Temperature profiles of the water column were obtained at one hour intervals along the CPR transects with an expendable bathythermograph (XBT) from 1977 onward. Ten meter temperature values before and after the central location of the CPR sample were distance weighted to interpolate a value for that position, essentially approximating the temperature where Penilia avirostris was captured by the CPR.

Climate variability was indexed with the winter phase of the North Atlantic Oscillation (NAO), the Gulf Stream North Wall Index (GSI), and the Atlantic Multidecadal Oscillation (AMO). The NAO is an index which is based on the difference of normalized sea level pressures between Lisbon, Portugal and Stykkisholmur/Reykjavik, 
Iceland from the months of December through March (Hurrell, 1995). The GSI is a measure of the position of the north wall of the Gulf Stream as it diverges from the North American coastline (Taylor et al., 1995). The AMO is a mode of natural variability occurring in the North Atlantic that is primarily associated with long duration changes in sea surface temperature (Kerr, 2000). These three indices of climate variability are all known to affect physical and biological measurements across the North Atlantic and are readily available online.

Spearman's rank correlation coefficients between the annual anomalies of Penilia avirostris abundance and the environmental variables were calculated within each broadscale survey subarea and along each CPR transect to measure the strength of association between them. Abundance anomalies were also correlated with one and two year lag periods of environmental measures to determine if conditions in preceding years affect the cladocerans's density. Additionally, bimonthly subsets of data were analyzed to determine if any of the factor(s) trigger seasonal abundance pulses.

\section{Results}

\section{Broad Scale Surveys}

Penilia avirostris abundance explodes in the southernmost waters of the ecosystem during summer (Fig. 2). Large numbers of the cladoceran suddenly appear in the MAB region during July-August, where near-shore samples frequently have more than one million individuals per $100 \mathrm{~m}^{3}$. P. avirostris numerically dominates the zooplankton community during these months, usually accounting for nearly $50 \%$ of the total mesozooplankton. Its numbers decline slowly through the autumn months and few are found during the winter and spring. Further north in the SNE region, its mean numbers are lower and they peak later in the year during September-October (Fig. 2). They also become nearly absent there during winter and measureable numbers do not reappear until the following summer. P. avirostris is not a major component of the GBK or GOM zooplankton community. It is usually absent from samples throughout most of the year, except for isolated and light catches that are most frequent in early autumn.

High numbers of Penilia avirostris can usually be found in coastal waters during July-August in decreasing southnorth and onshore-offshore abundance gradients (Fig. 3). The inshore concentrations extend further northward into SNE waters during September-October, forming three

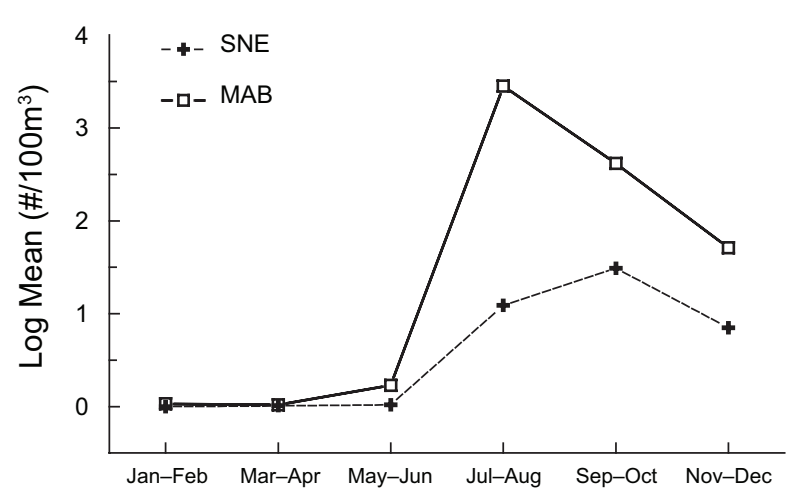

Fig. 2. The time series average annual $\log _{10}$ abundance cycle of Penilia avirostris for the Southern New England (SNE) and Middle Atlantic Bight (MAB) subareas of the U.S. Northeast shelf ecosystem.

to four bands of decreasing inshore-offshore abundance gradients south of Cape Cod. The bands begin to weaken in November-December, dissolving into isolated pockets of high numbers in MAB inshore waters (Fig. 3). Low catches of $P$. avirostris were captured throughout GBK and most of the GOM at some points in the time series, especially during early autumn. Moderate concentrations were occasionally found in coastal waters near Cape Cod. During the first half of the year, $P$. avirostris is sparsely distributed throughout the ecosystem and is often absent over widespread areas (Fig. 3).

No persistent, long-term abundance trends of Penilia avirostris were evident for the time series. Patterns were similar $(r=0.56, p<0.01)$ in both the MAB and SNE regions; with mostly above average levels in the late 1970s and early 1980s, low from the mid-1980s into the early 1990s, and highly variable thereafter through 2009 (Fig. 4). P. avirostris abundance in the GBK and GOM regions was too sparse to measure meaningful interannual trends.

Distribution maps contrasting the first and last decades of the time series suggest that the summer distribution of Penilia avirostris has changed in recent years (Fig. 5). During the 2000s, there was a northward and offshore extension of the high concentrations typically found in the MAB during the summer season. From 1977-86, the northern extent of the high density cluster was located in central New Jersey, while in the 2000s it had moved northward to about $75 \mathrm{~km}$ off Long Island (Fig. 5). The maps also indicate that the cladoceran had a more widespread distribution over the northern half of the ecosystem during the 2000s (Fig. 5). 
KANE: Abundance and Distribution Trends of the Cladoceran in the US Northeast Shelf Ecosystem
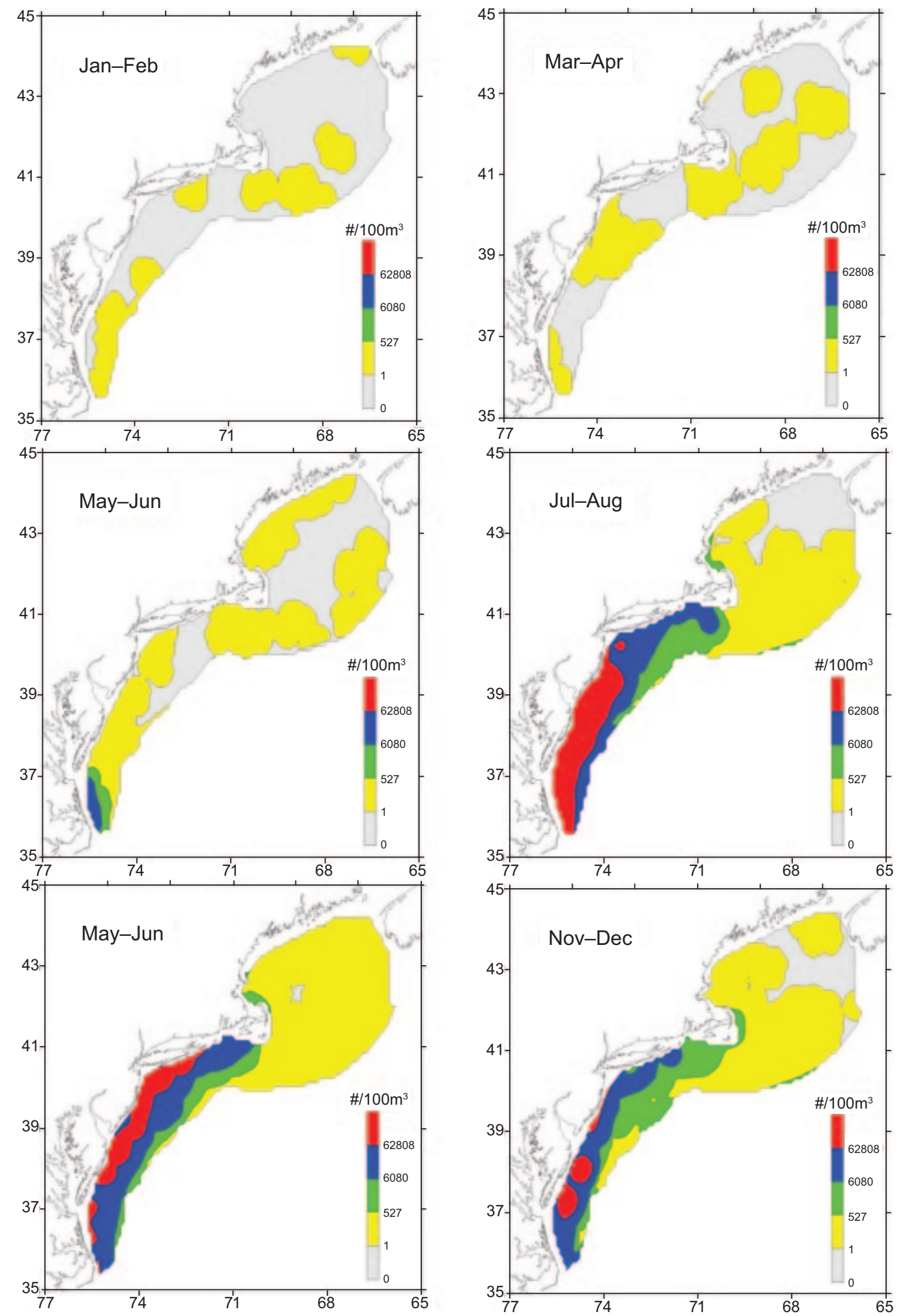

Fig. 3. Bimonthly composite distribution and abundance of Penilia avirostris in the U. S. Northeast shelf ecosystem. 


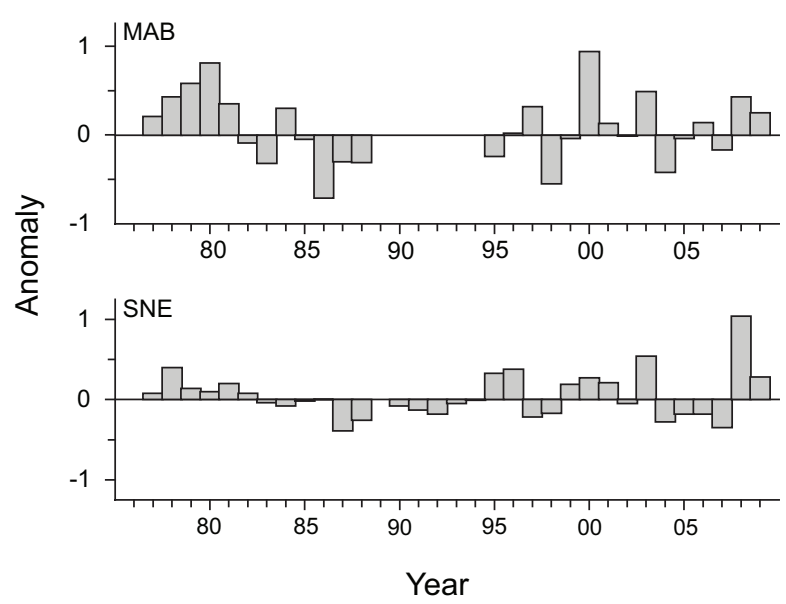

Fig. 4. Annual anomalies of Penilia avirostris abundance in the MAB (Middle Atlantic Bight) and SNE (Southern New England) regions. Each bar represents the annual mean of survey log abundance anomalies.

\section{CPR Surveys}

High numbers of Penilia avirostris abruptly appear in MA CPR shelf samples during August, with concentrations located in coastal waters (Fig. 6). Numbers slowly decline through the early autumn months, decline sharply in late autumn, and are completely absent from January through June. It was captured on only one July survey (2008) during the 34 year sampling period. The cladocerans' abundance was much lower in slope waters (Fig. 6), identified on only $1.6 \%$ of the silk segments examined there during the time series. In 1985, it was first identified seaward of the shelf break and since then has been present in over half of the years. P. avirostris has never been found in GOM CPR samples.

Interannual variability in MA shelf samples waters was similar (Fig. 7), but not identical to the broadscale survey patterns (Fig. 4). Low years were more prevalent in the late 1970s-early 1980s, while above average years dominated the 1990s. Distribution along the transect was stable throughout the time series, with no major shifts in spatial patterns (data not shown).

\section{Environmental and Climate Variables}

There were no significant $(p<0.01)$ correlations between the annual anomalies of Penilia avirostris abundance and the environmental variables measured in both the MAB and SNE regions. Lagging the environmental variables from one to three years did not improve correlations. The results were the same when the cladocerans' interannual patterns were compared to the annual and lagged values of the NAO, GSI, and AMO indices.
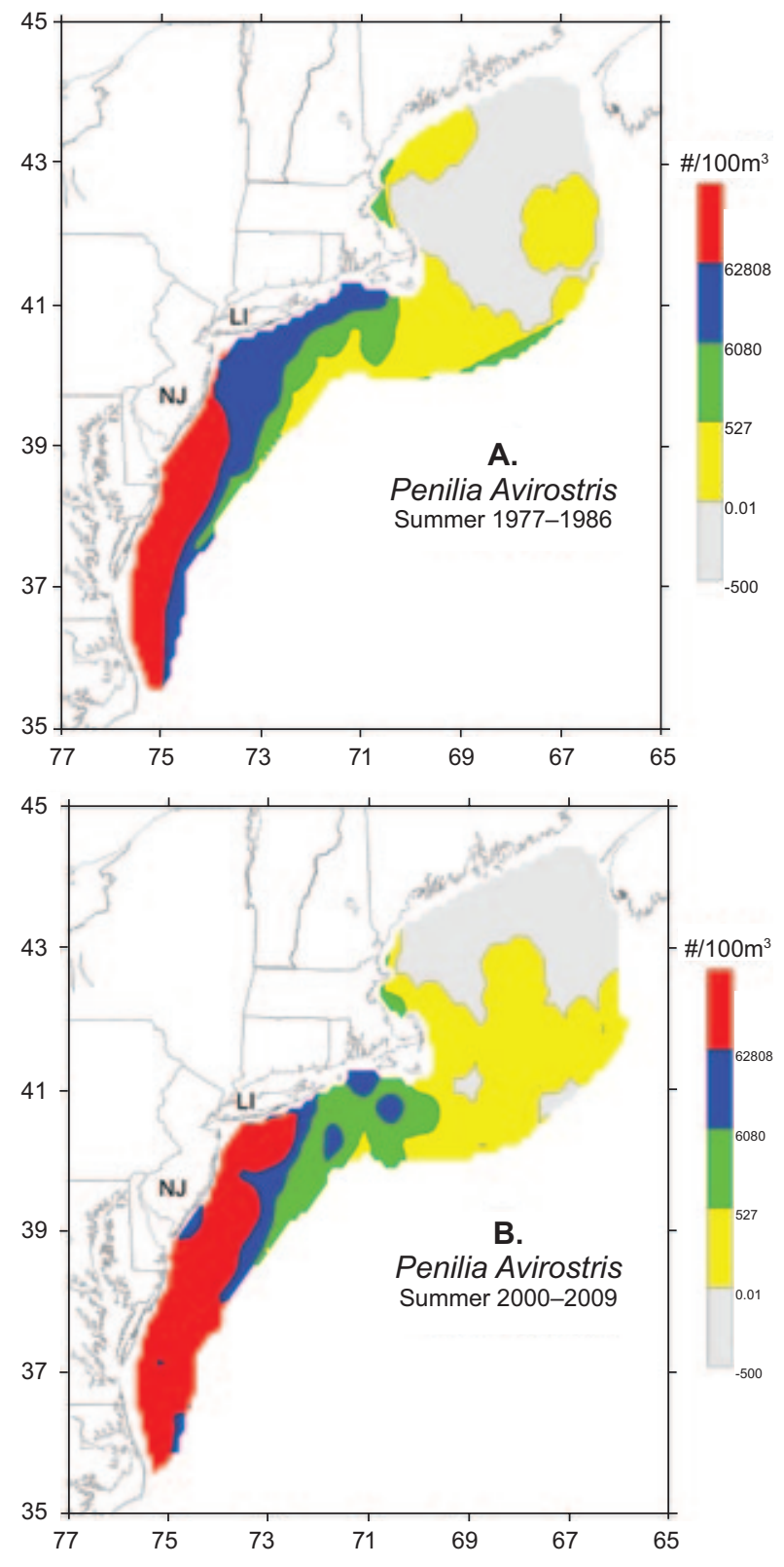

Fig. 5. Average summer (July-August) distribution and abundance of Penilia avirostris in the U. S. Northeast shelf ecosystem during A) 1977-1986 and B) 2000-2009.

A correlation analysis applied to data collected exclusively in July and August revealed that surface temperature and water stratification were both significantly correlated $(p<0.01)$ with Penilia avirostris abundance in the MAB and SNE regions, though correlation coefficients were only moderately high (Table 1). Similar to P. avirostris, these variables both reach their seasonal peak during this time period. The relationship between the variables are not strongly linear, but temperature and stratification have a key role defining the animals life history. 
Partitiioning the data by $4{ }^{\circ} \mathrm{C}$ intervals readily shows the cladocerans' abundance is strongly associated with elevated temperatures (Fig. 8). The cladocerans' density was also significantly negatively correlated with surface salinity measurements (Table 1).

In August, abundance along the shelf portion of the MA CPR transect was significantly correlated $(p=0.02)$ with water temperature at $10 \mathrm{~m}$ depth, though the correlation coefficient was also only moderate $(r=0.23)$. The two variables were not significantly correlated in the other eleven months.

\section{Discussion}

Penilia avirostris has a distinct seasonal cycle in the southern half of the US Northeast shelf ecosystem. It suddenly appears in July-August with the highest numbers found in coastal regions. It forms a dense population that slowly diminishes through the autumn months. The cladoceran then essentially disappears from the zooplankton community during winter and does not return until its abrupt appearance in summer. This seasonal unimodal pattern is the typical annual cycle observed for P. avirostris in temperate waters (Lochhead, 1954; Lipej et al., 1997; Atienza et al., 2008).

Temperature probably is the major factor that controls Penilia avirostris distribution because its populations are restricted to the warmer waters of its northern and southern ranges (Atienza et al., 2008). This is true in the US northeast ecosystem, where numbers are highest in the warmer, southernmost waters of the region; minimal in the cooler waters of the more northern GBK and GOM regions. This study also found significant correlations between abundance and temperature during its summer pulse, though coefficients were only moderately high. Coefficient values were likely depressed by the cladocerans sometimes, highly irregular or patchy distribution. During the summer months, $P$. avirostris occasionally will be absent at stations adjacent to ones where concentrations of over one million individuals per $100 \mathrm{~m}^{3}$ have been measured.
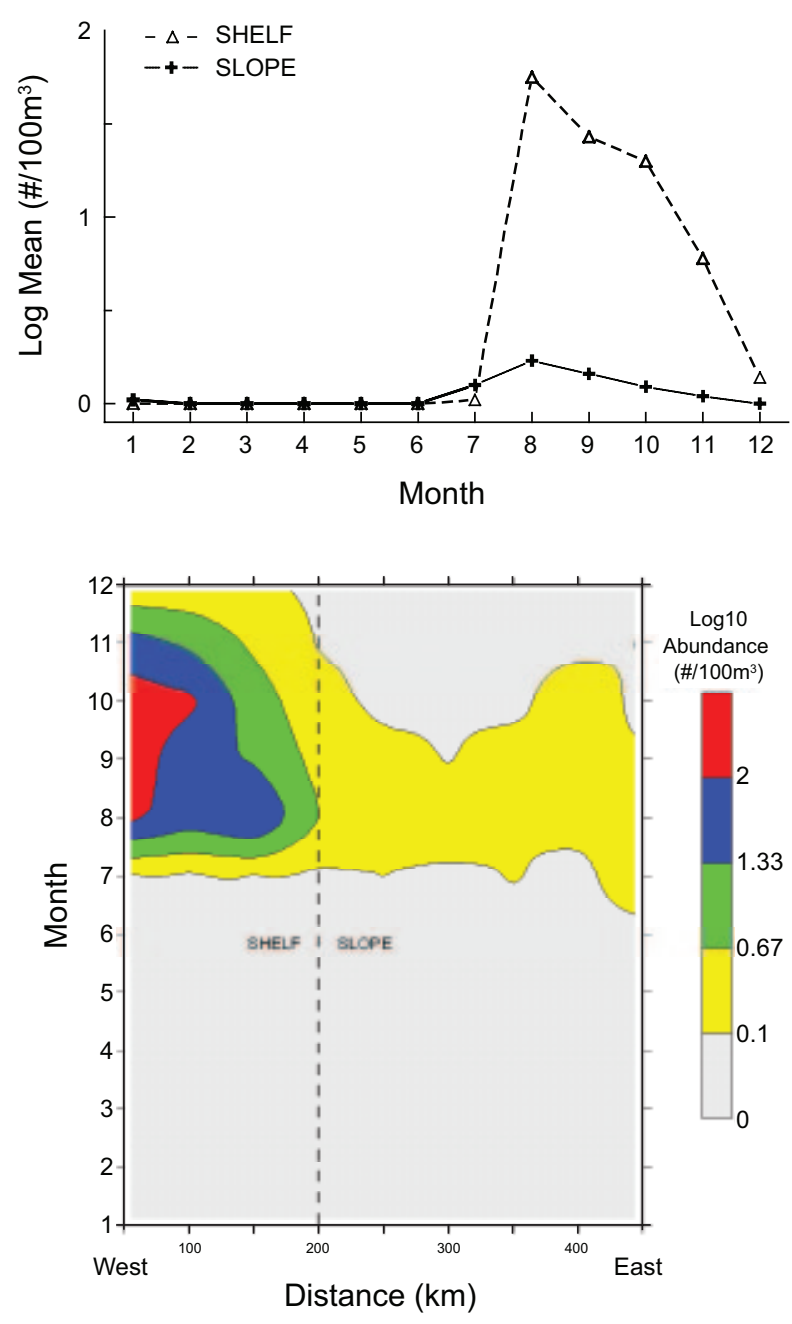

Fig. 6. Time series shelf and slope water monthly mean abundance (upper panel) and seasonal distribution (lower panel) of Penilia avirostris along the MidAtlantic CPR transect.

The population of Penilia avirostris must be renewed each year by the successful production and hatching of its resting eggs. The cladocerans' strong seasonal cycle suggests that temperature is the key factor initiating egg hatching. After finding no P. avirostris in the GOM and

Table 1. Spearmann partial (bottom depth) correlation coefficients between Penilia avirostris $\log _{10}$ abundance and environmental variables measured on broad scale surveys during July-August. An asterisk indicates the correlations were significant $(p<0.01)$. (Abbreviation key: temp. $=$ temperature, strat. $=$ stratification)

\begin{tabular}{lccccc}
\hline \hline Region & Surface temp. & Bottom temp & $\begin{array}{l}\text { Surface } \\
\text { salinity }\end{array}$ & $\begin{array}{l}\text { Bottom } \\
\text { salinity }\end{array}$ & Strat \\
\hline MAB & $0.16^{*}$ & -0.01 & -0.08 & -0.01 & $0.22^{*}$ \\
SNE & $0.35^{*}$ & -0.01 & $-0.25^{*}$ & 0.03 & $0.34^{*}$ \\
\hline
\end{tabular}




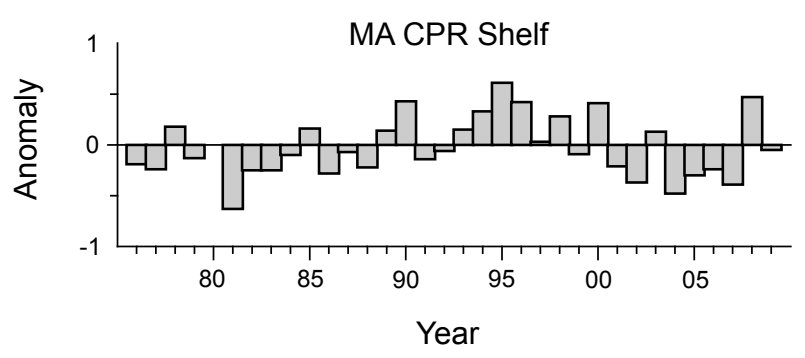

Fig. 7. Annual anomalies of Penilia avirostris shelf water abundance along the Mid-Atlantic CPR transect. Each bar represents the annual mean of survey log abundance anomalies.

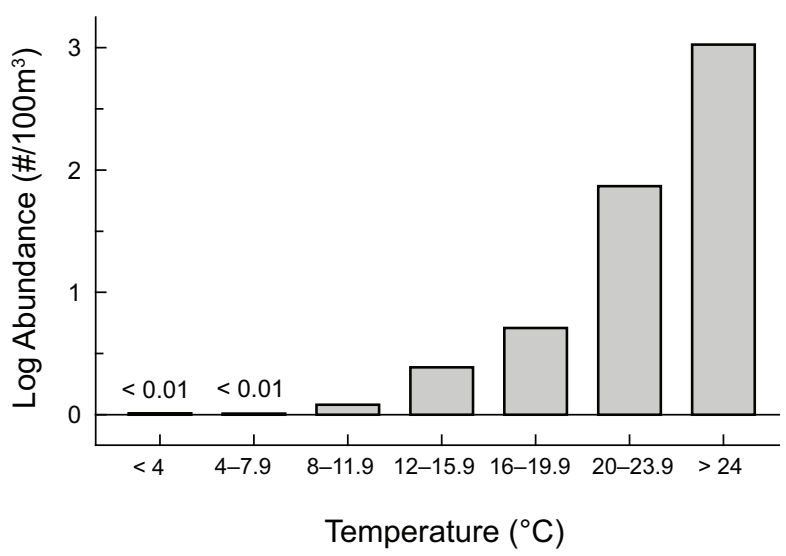

Fig. 8. Broad scale survey mean abundance of Penilia avirostris by surface temperature interval.

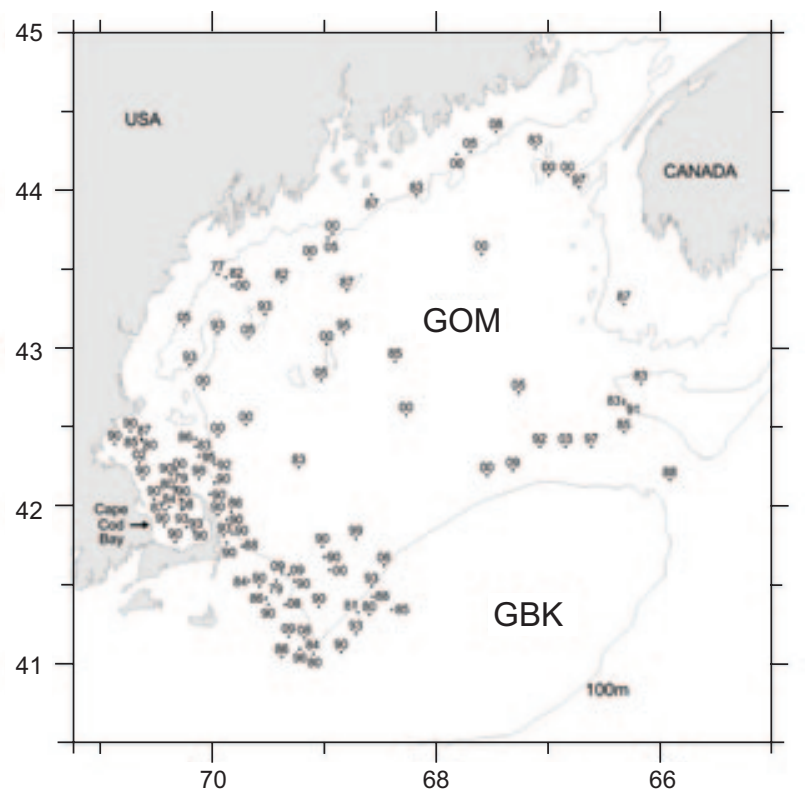

Fig. 9. Locations of Gulf of Maine stations where Penilia avirostris was identified in samples collected on broad scale surveys of the region from 1977-2009. Points are labeled with year of capture. seaward of the shelf break during 1980 and 1981, Colton (1985) suggested that bottom temperatures must be at least $10^{\circ} \mathrm{C}$ before development of resting eggs begins. However, this study found no correlation between $P$. avirostris abundance and bottom temperatures during the summer awakening period. High numbers of the cladoceran were often found in offshore waters where the bottom temperatures were below $10^{\circ} \mathrm{C}$. However, maybe these specimens were advected offshore from warmer inshore areas by prevailing westerly winds. Furthermore, as noted earlier, the cladocerans' patchy distribution could mask significant correlations between variables. Laboratory studies are needed to verify that the hatching success of $P$. avirostris resting eggs is independent from bottom temperature values.

Decades ago Lochhead (1954) reviewed the literature and observed that Penilia avirostris becomes permanently established only where the mean surface temperature reaches at least $21^{\circ} \mathrm{C}$. He hypothesized that this is the minimal temperature necessary to build up a minimum population density sufficiently high to assure the survival of at least a few individuals, or resting eggs, through winter. This hypothesis is applicable today in the Northeast Atlantic shelf ecosystem. Persistent breeding populations have yet to be established in the GOM and GBK regions where mean surface temperature peaks at $16.8^{\circ} \mathrm{C}$ and $17.4^{\circ} \mathrm{C}$ respectively, while further south where $P$. avirostris thrives, it rises above the $21^{\circ} \mathrm{C}$ threshold during summer. Further evidence for this temperature minimum can be found further north in the Gulf of St Lawrence off Prince Edward Island. $P$ avirostris transported there by ballast waters has been able to establish a permanent breeding community because a warm microclimate elevates temperatures there to $21^{\circ} \mathrm{C}$ (Bernier and Locke, 2006). However, this does not explain why P. avirostris abundance was low and sparsely distributed in slope waters where surface temperatures exceed $21^{\circ} \mathrm{C}$ for several months of the year (Jossi and Benway, 2003). Another factor other than water temperature probably limits its distribution and abundance in offshore waters. Since there usually is an eight-fold decrease in phytoplankton biomass across the shelf-slope front in ecosystem waters (O'Reilly and Zetlin, 1998), food limitation may restrict its offshore abundance.

Other studies have also proposed that food availability is an important factor affecting the spatial distribution and seasonal cycle of Penilia avirostris (Lipej et al., 1997; Calbert et al., 2001). Further support for this hypothesis can be inferred from the strong decreasing inshoreoffshore abundance gradients observed in this study, echoing the phytoplankton gradients that characterize the 
region (O'Reilly and Zetlin, 1998). This study also found that $P$. avirostris abundance was closely aligned with the seasonal cycle of water column stratification. In the highly stratified waters of summer, thermocline concentrations of chlorophyll $a$ are often several times higher in the waters above and below it (O'Reilly and Zetlin, 1998). This subsurface maximum is fueled by adequate light and food supplied through diffusion from nutrient rich waters below or from nearshore mixing events. This productive layer is ubiquitous and represents a concentrated source of nutrition for all herbivores (O'Reilly and Zetlin, 1998). It is especially rich in nanoplanktonic autotrophs, the preferred prey of $P$. avirostris (Atienza et al., 2006). The high temperatures and phytoplankton biomass found in stratified waters likely combine to fuel the explosive growth of $P$. avirostris during summer.

Analysis of data collected on broad scale surveys in 1980-81 found isolated patches of Penilia avirostris on GBK, establishing its first recorded occurrence in the region and an eastward extension of its previous-reported distribution (Colton, 1985). It was absent in the GOM and, since earlier plankton surveys of the region also did not report its presence (Bigelow, 1926; Fish and Johnson, 1937; Sherman, 1980), Colton (1985) was able to 'state unequivocally that Penilia does not occur in the Gulf of Maine'. However, the present study identified P. avirostris in $112 \mathrm{GOM}$ samples (occurrence $=1.8 \%$ ). It was first recorded in 1977 and has been found present in all but five years of the time series. These were usually light catches $\left(<1000 / 100 \mathrm{~m}^{3}\right)$ at isolated stations, predominately found in the southeastern waters of the region during autumn months (Fig. 9). It was most abundant in 1990 when dense concentrations were recorded in Cape Cod Bay on Oct. 24 $\left(55196 / 100 \mathrm{~m}^{3}\right)$ and again on Nov. $2\left(118434 / 100 \mathrm{~m}^{3}\right)$. In all, $P$. avirostris was identified at 23 stations along the Massachusetts coast during October-November of 1990 (Fig. 9).

Penilia avirostris now ranges northward into the GOM, though it does not appear to have established a persistent, breeding population in the region. P. avirostris has also not become strongly established on GBK, where it is found in only low numbers at scattered locations (occurrence $=1.6 \%$ ). However, if the current warming trend in the region continues (Friedland and Hare, 2007), it may become a permanent resident and be more abundant. Already, the high summer concentrations in southern waters have begun to expand northward in the 2000s. Since certain aspects of its life history enable it to quickly become established in regions that are warming, P. avirostris may be a sentinel species for climate change in the North Atlantic. Future monitoring efforts will need to focus on the spread and influence of this prolific cladoceran within ecosystem waters.

\section{Acknowledgements}

I thank the numerous people who worked hard to collect and process the data used in this report.

\section{References}

ATIENZA, D., E. SAIZ1, A. SKOVGAARD, I. TREPATI and A. CALBET. 2008. Life history and population dynamics of the marine cladoceran Penilia avirostris (Branchiopoda: Cladocera) in the Catalan Sea (NW Mediterranean). J. Plankton Res., 30: 345-357. http://dx.doi.org/10.1093/ plankt/fbm109

ATIENZA, D., E. SAIZ and A. CALBET. 2006. Feeding ecology of the marine cladoceran Penilia avirostris. Natural diets, daily ration and prey selectivity. Mar. Ecol. Prog. Ser., 315: 211-220. http://dx.doi.org/10.3354/meps315211

BIGELOW, H. B. 1926. Plankton of the offshore waters of the Gulf of Maine. Bull. Bur. Comm. Fish. XL Part 2. Gov't Printing Office, Washington, D. C., 509 p. http://dx.doi. org/10.5962/bhl.title.4192 PMid:17773664

BERNIER, R. and A. LOCKE. 2006. New record of distribution of Penilia avirostris Dana 1849, in the Northwest Atlantic. Crustaceana, 79: 949-959. http://dx.doi. org/10.1163/156854006778815928

CALBERT, A., E. GARRIDO, M. SAIZ, M. ALCARAZ and C. M. DUARTE. 2001. Annual zooplankton succession in coastal NW Mediterranean waters: the importance of the smaller size fractions. J. Plankton Res., 23: 319-331. http:// dx.doi.org/10.1093/plankt/23.3.319

COLEBROOK, J. M. 1975. Continuous plankton recorder survey: Automatic data processing methods. Bull. Mar. Ecol., 8: 123-142.

COLTON, J. B., JR. 1985. Eastward extension of the distribution of the marine cladoceran (Penilia avirostris) in the Northwest Atlantic: a case of ecesis? J. Northw. Atl. Fish. Sci., 6: 141-148. http://dx.doi.org/10.2960/J.v6.a14

FISH, C. J. and M. W. JOHNSON. 1937. The biology of the plankton populations in the Bay of Fundy and Gulf of Maine with special reference to production and distribution. J. Biol. Board Can., 3: 189-322. http://dx.doi.org/10.1139/ f37-015

FRIEDLAND, K. D. and J.A. HARE. 2007. Long-term trends and regime shifts in sea surface temperature on the continental shelf of the northeast United States. Cont. Shelf Res., 27: 2313-2328. http://dx.doi.org/10.1016/j.csr.2007.06.001

HARDY, A. C. 1939. Ecological investigations with the continuous plankton recorder. Object, plan, and methods. Hull. Bull. Mar. Ecol., 1: 1-57

HURRELL, J. W. 1995. Decadal trends in the North Atlantic Oscillation: Regional temperatures and precipitation. Science, 269: 676-679. http://dx.doi.org/10.1126/ science.269.5224.676. PMid:17758812

INGHAM, M. C., R. S. ARMSTRONG, J. L. CHAMBERLIN, et al. 1982. Summary of the Physical Oceanographic Processes and Features pertinent to Pollution Distribution in 
the Coastal and Offshore Waters of the Northeastern United States, Virginia to Maine. NOAA Tech. Mem., NMFS-F/ NEC-17 322 p.

JOHNS, D. G., M. EDWARDS, W. GREVE and A.W.G. SJOHN. 2005. Increasing prevalence of the marine cladoceran Penilia avirostris (Dana, 1852) in the North Sea. Helgoland Mar. Res., 59: 214-218. http://dx.doi.org/10.1007/s10152-0050221-y

JOSSI, J. W. and R. L. BENWAY. 2003. Variability of Temperature and Salinity in the Middle Atlantic Bight and Gulf of Maine based on data collected as part of the MARMAP ships of Opportunity program, 1978-2001. NOAA Tech. Mem, NMFS-NE-172, $92 \mathrm{p}$.

KANE, J. 2003. Spatial and temporal abundance patterns for late-stage copepodites of Metridia lucens (Copepoda: Calanoida). J. Plankton Res., 25: 151-167. http://dx.doi. org/10.1093/plankt/25.2.151

KANE, J. 2011. Inter-decadal variability of zoplankton abundance in the Middle Atlantic Bight. J. Northw. Atl. Fish. Sci., 43: 81-92. http://dx.doi.org/10.2960/J.v43.m674

KATECHAKIS, A., H. STIBOR, U. SOMMER and T. HANSEN. 2004. Feeding selectivities and food niche separation of Acartia clausi, Penilia avirostris (Crustacea) and Doliolum denticulatum (Thaliacea) in Blanes Bay (Catalan Sea, NW Mediterranean). J. Plankton Res., 26: 589-603. http://dx.doi. org/10.1093/plankt/fbh062

KERR, R. A. 2000. A North Atlantic climate pacemaker for the centuries. Science, 288: 1984-1985. http://dx.doi. org/10.1126/science.288.5473.1984. PMid:17835110

LIPEJ, L., P. MOZETIC, V. TURK and A. MALEJ. 1997. The trophic role of the marine cladoceran Penilia avirostris in the Gulf of Trieste. Hydrobiol., 360: 197-203. http://dx.doi. org/10.1023/A:1003180030116

LOCHHEAD, J. H. 1954. On the distribution of a marine cladoceran, Penilia avirostris Dana (Crustacea, Branchiopoda), with a note on its reported bioluminescence.
Biol. Bull., Woods Hole, 107: 92-105. http://dx.doi. org/10.2307/1538633

O'REILLY, J. E. and C. ZETLIN. 1998. Seasonal, horizontal, and vertical distribution of phytoplankton chlorophyll $a$ in the Northeast U.S. Continental Shelf Ecosystem. NOAA Tech. Rep. NMFS 139, 128p.

ROSE, K., J. C. ROFF and R. R. HOPCROFT. 2004. Production of Penilia avirostris in Kingston Harbour, Jamaica. J. Plankton Res., 26: 605-615. http://dx.doi.org/10.1093/ plankt/fbh059

SHERMAN, K. 1980. MARMAP, a fisheries ecosystem study in the NW Atlantic: fluctuations in the icthyoplanktonzooplankton components and their potential for impact on the system. In: Advanced Concepts on Ocean Measurements for Marine Biology, F. P. Diemer, F. J. Vernberg and D. Z. Mirkes (eds.). Belle W. Baruch Institute for Marine Biology and Coastal Research, University of South Carolina Press, Columbia, S.C., p. 9-37.

SIBUNKA, J. D. and M. J. SILVERMAN. 1984. MARMAP surveys of the continental shelf from Cape Hatteras, North Carolina, to Cape Sable, Nova Scotia (1977-1983). Atlas No. 1. Summary of operations. NOAA Tech. Mem., NMFS-F/ NEC-33.

SIBUNKA, J. D. and M. J. SILVERMAN. 1989. MARMAP surveys of the continental shelf from Cape Hatteras, North Carolina, to Cape Sable, Nova Scotia (1984-1987). Atlas No. 3. Summary of operations. NOAA Tech. Mem., NMFS-F/ NEC-68.

TANG, K. W., C. C. CHEN and C. K. WONG. 1995. Distribution and biology of marine cladocerans in the coastal waters of southern China. Hydrobiol., 507: 99-107. http://dx.doi. org/10.1007/BF00032001

TAYLOR, A. H. 1995. North-south shifts of the Gulf Stream and their climate connection with the abundance of zooplankton in the UK and its surrounding seas. ICES J. Mar. Sci., 52: 711-721. http://dx.doi.org/10.1016/1054-3139(95)80084-0 